\title{
Preliminary Study on a RT-PCR Method for the Equine Infectious Anemia Virus Detection
}

\author{
Qin TANG ${ }^{1}$, Han ZHANG ${ }^{1}$, Jia-qi HAN ${ }^{1}$, Li -rui LI' ${ }^{2}$, Ting-chuan LIU ${ }^{1}$, \\ Jing $X^{1}{ }^{1}$, Gang $Y^{1}$, Yin $W^{\prime} N^{1}{ }^{1}$, Xue-ping $Y A O^{1}$ and Ze-xiao \\ $\mathrm{YANG}^{1, *}$ \\ ${ }^{1}$ Sichuan Agricultural University, Chengdu, China \\ ${ }^{2}$ Chengdu Provincial Center for Animal Disease Prevention and Control Chengdu, \\ China \\ ${ }^{*}$ Corresponding author
}

Keywords: Equine infectious anemia, RT-PCR, Detection.

\begin{abstract}
To develop a Reverse Transcription-Polymerase Chain Reaction (RT-PCR) method for quick detecting equine infectious anemia virus (EIAV), according the conserved sequences of EIAV gag gene which published in GenBank, 2 specific RT-PCR primers and 8 extension primers were designed and synthesized. A DNA fragment of EIAV gag gene about 370bp was synthesized in vitro by overlapping PCR, then the RT-PCR method for equine infectious anemia detection was established preliminarily through optimizing the reaction conditions, sensitivity and specificity experiments, and validity test. The results showed that the method for the EIAV has a good specificity and sensitivity, and the reaction product was about 370bp DNA electro phoretic band. This method can detect the EIAV target fragment about 119 copies $/ \mu \mathrm{L}$. There are no amplification for the detection of Proteus, Actinobacillus, Salmonella, Escherichia coli, Stenotrophomonasmalt ophilia and Streptococcus type II, and the results showed positive reaction for Equine infectious anemia test antigen detection.
\end{abstract}

\section{Introduction}

Equine infectious anemia is an infectious disease of horse animal caused by equine infectious anemia virus (EIAV), also known as swamp fever, which was an OIE list B disease. Equine infectious anemia was first discovered in France in 1843 and spread around the world after World War II. Although there are no new morbidity of clinical cases appeared and the disease is under control in China nowadays [1], EIA is still the important disease for horse-breeding, and is listed as the second class animal disease in China. EIAV is a member of retrovididae (Retroviridae) lentivirus (Lentivirus). Viral particles were spherical, with capsule, the diameter of $90 \sim 120 \mathrm{~nm}$, capsule thickness of about $9 \mathrm{~nm}$, outside the capsule surface of a small surface of the fiber. The center of the virus particle has a diameter of $40 \sim 60 \mathrm{~nm}$ nucleus (nucleus), it is conical. EIAV nucleic acid is a single stranded linear RNA, which is divided into two fragments, the virus depends on the proliferation of DNA [2].

Swamp fever mainly occurs in horses, donkeys and mules, other livestock, poultry and wild animals are no natural infection report, but there are manual records of infection. Sick horses and poisonous horses are the main source of infection of this disease. The sick animals in the fever period have the highest concentration of blood and visceral toxicity, the largest detoxification, the strongest infection (chronic disease horse). And in apparent infection horse will have the virus and spread the disease for a 
long time. The disease is mainly local epidemic or distributed. Generally there is no strict seasonal and regional spread discipline, but in summer and autumn and forests with more blood-sucking insects, swamps will be more popular. In the new epidemic area it is more common to infect acute type disease, and has high mortality, but the old epidemic area is chronic and hidden type, with low mortality [2, 3].

Today, the EIA control is based on identification of in apparent carriers by detection of antibodies to EIAV in serologic tests, generally the agar gel immune-diffusion (AGID) test or enzyme-linked immune sorbent assay (ELISA)-based tests, complement test, fluorescent antibody test, etc. In international trade, the designated diagnostic method is the AGID test, alternative diagnostic method is enzyme-linked immuno-sorbent assay. AGID test requires a second day to observe, it spends a long time and the sensitivity is not high. What's more, there are a variety of factors that can affect the agar diffusion test specificity, sensitivity, accuracy, and sometimes the results cannot be judged[4-6]. As a molecular method for the gene of EIAV detection, Reverse Transcription-Polymerase Chain Reaction (RT-PCR) amplification is a very sensitive technique that can detect very low copy number of target gene fragment. To provide reference and efficient method for EIAV rapid detection. Here the EIAV non-structural protein gene conserved fragments was synthesized and a RT-PCR method of EIAV detection was established.

\section{Materials and Methods}

\section{Reagents and Samples}

pMD19-T vector, dNTP mixture, DL 2000 marker, TaKaRarTaqTM, RNAiso Plus, RNA LA PCRTM Kit (AMV) Ver.1.1 (DRR012A) were purchased from TaKaRa Biotechnology (Dalian) Co., Ltd. .2×TaqPCRMastermix , DH5 $\alpha$ competent, TIAN Prep Mini Plasmid Kit (DP103), TIANgel Midi Purification Kit (DP209) and Pfu DNA polymerase from Chengdu fly grams (day Thailand) Co., Ltd.

\section{Primer Preparation}

Based on the EIAV genome sequence published in GenBank, 8 PCR primers and 2 specific RT-PCR primers were designed by Genestar software (see table 1).

\section{Synthesis of EIAV Target Gene Fragment [7]}

The primary extension reaction volume $(50 \mu \mathrm{L})$ contains $5 \mu \mathrm{L} 10 \times \mathrm{Pfu}$ DNA polymerase buffer, $4 \mu \mathrm{L}$ of dNTPs $(10 \mu \mathrm{mol} / \mathrm{L}), 1 \mu \mathrm{L}(10 \mu \mathrm{mol} / \mathrm{L})$ of each of the overlappingoligo primers (F1/R1, F2/R2, F3/R3, F4/R4 or F5/R5), $1 \mu$ Lof Pfu DNA polymerase, and $38 \mu \mathrm{L}$ ddH2O. The reaction conditions were $94^{\circ} \mathrm{C}$ for 30 s and $72^{\circ} \mathrm{C}$ for $15 \mathrm{~min}$.

And the secondary extension reaction volume $(50 \mu \mathrm{L})$ containing $1 \mu \mathrm{L} 10 \times \mathrm{Pfu}$ DNA polymerase buffer, $4 \mu \mathrm{L}$ of dNTPs $(10 \mu \mathrm{mol} / \mathrm{L}), 1 \mu \mathrm{L}$ of Pfu DNA polymerase, and $22 \mu \mathrm{L}$ of each of the two overlap previous extension reaction products. The reaction conditions were $94^{\circ} \mathrm{C}$ for $30 \mathrm{~s}$ and $72^{\circ} \mathrm{C}$ for $15 \mathrm{~min}$.

The PCR reaction volume $(50 \mu \mathrm{L})$ containing $5 \mu \mathrm{L} 10 \times$ rTaqTM DNA polymerase buffer, $1 \mu \mathrm{L}(10 \mu \mathrm{mol} / \mathrm{L})$ of each of the primers (P1/P2), $4 \mu \mathrm{LdNTP}(10 \mu \mathrm{mol} / \mathrm{L}), 1 \mu \mathrm{L}$ of the last secondary extension reaction products and $38 \mu \mathrm{L}$ ddH2O. The PCR was conducted as follows: denaturing at $95^{\circ} \mathrm{C}$ for $5 \mathrm{~min}$, followed by 35 cycles at $94^{\circ} \mathrm{C}$ for $40 \mathrm{~s}, 56^{\circ} \mathrm{C}$ for $30 \mathrm{~s}$, and $72^{\circ} \mathrm{C}$ for $45 \mathrm{~s}$, then terminated by an elongation at $72^{\circ} \mathrm{C}$ for $8 \mathrm{~min}$. In all, $5 \mu \mathrm{L}$ of PCR products were analyzed using $10 \mathrm{~g} / \mathrm{L}$ agarose electrophoresis, then photographed under a UV imaging system (Bio-Rad). 
The PCR products were subsequently separated and purified according to the TIANgel Midi Purification Kit(DP209) instructions and were then directly cloned into thepMD19-T vector followed by a transformation into theDH5 $\alpha$ competent cells. Then, the positive clones were amplified from Amp + LB plates and the recombinant plasmids were extracted by TIANpre Mini Plasmid Kit (DP103).After the recombinant plasmids was identified by pMD-19T vector universal primers. A recombinant plasmid (named pMD19-T-EIVA) identified by PCR and identified as positive was sent to Beijing LiuheHuayuan Gene Technology Co., Ltd. for sequencing. And the positive recombinant plasmid was extracted and stored at $-20^{\circ} \mathrm{C}$ for the template used in this study[7].

\section{Optimizing RT-PCR Reaction Conditions}

The identified EIAV positive plasmid (pMD19-T-EIVA) was used as a template, and $1.5 \mu \mathrm{L}$ of the reaction system of $25 \mu \mathrm{L}: 2 \times$ Taq PCR Mastermix $12.5 \mu \mathrm{L}, \mathrm{P} 1 / \mathrm{P} 2$ $(10 \mu \mathrm{mol} / \mathrm{L}), 1 \mu \mathrm{L}$ of the final secondary extension reaction product $8.5 \mu \mathrm{L}$ ddH2O, after mixing, $95^{\circ} \mathrm{C} 3 \min , 94^{\circ} \mathrm{C} 40 \mathrm{~s}, 56^{\circ} \mathrm{C} 40 \mathrm{~s}, 72^{\circ} \mathrm{C} 45 \mathrm{~s}, 30$ cycles, $72{ }^{\circ} \mathrm{C} 8 \mathrm{~min}$. Then, the conditions such as annealing temperature, cycle condition, and cycle number and primer concentration were optimized.

\section{Sensitivity Test}

The positive recombinant plasmid (pMD19-T-EIAV) was extracted as a detection template and quantified with ND-1000 UV spectrophotometer. The DNA fragment was diluted to $1.19 \times 10^{6}, 1.19 \times 10^{5}, 1.19 \times 10^{4} \mathrm{~m}, 1.19 \times 10^{3}, 119$ and $11.9 \mathrm{copies} / \mu \mathrm{L}$, respectively, according to the established reaction conditions.

\section{Specificity Test}

The specificity tests of EIAV RT-PCR was performed through comparing the positive recombinant plasmids to Proteus, Salmonella, Escherichia coli, etc. common rabbit pathogens. RNA and DNA (cDNA) templates were prepared using a commonly reported method.

\section{Effective Experiment}

Extracting RNA from Equine infectious anemia reagent agar diffusion test antigen with RNA is oPlus Reagent (BK1501).According Primerscript RT Reagent Kit (BK1901) instructions to reverse transcribed cDNA. Then the validity test was carried out using the established PCR reaction conditions and procedures.

\section{Results}

\section{Identification of Target Genes}

The target gag fragment of 370bp of EIAV was amplified using overlapping PCR, as shown in Fig. 1A, and its recombinant plasmids identified by PCRs, The expected size of the band was amplified at 500bp (which contained 370bp of the target gene and the T vector on the 140bp sequence, see Fig. 1B). The sequencing result (see Fig. 2) showed the $100 \%$ same as the EIAV gene sequences which had published in GenBank by Blast alignment analysis. 
Table 1. Primers used for EIAV RT-PCR study

\begin{tabular}{|c|c|c|c|}
\hline Primer name & Sequence $\left(5^{\prime}-3{ }^{\prime}\right)$ & $\begin{array}{r}\text { Products } \\
\text { Size(bp) }\end{array}$ & $\begin{array}{c}\text { Refere } \\
\text { nce } \\
\text { sequenc } \\
\text { e }\end{array}$ \\
\hline $\mathrm{P} 1$ & TCAAGAAGTTAGAGAAGGTG & 370 & $\begin{array}{l}\text { GQ923 } \\
952\end{array}$ \\
\hline $\mathrm{P} 2$ & CTGTTTCCAGCCCCATCTA & & \\
\hline $\mathrm{F} 1$ & $\begin{array}{l}\text { GAAGTTAGAGAAGGTGACGGTACAAGGGTC } \\
\text { TCAGAAATTAACTACTGGTAACTGTAATT }\end{array}$ & & \\
\hline $\mathrm{F} 2$ & $\begin{array}{l}\text { GATACCAACTTTGTAAAAGAAAAGGACTGG } \\
\text { CAGCTGAGGGATGTCATTCCATTGCTGGA }\end{array}$ & & \\
\hline F3 & $\begin{array}{l}\text { AAAGAGAGGCCTTTGAAAGAACATGGTGGG } \\
\text { CAATTTCTGCTGTAAAGATGGGCCTCCAG }\end{array}$ & & \\
\hline F4 & $\begin{array}{l}\text { ATTCCAGCTCCTAAGAGCGAAATATGAAAA } \\
\text { GAAGACTGCTAATAAAAAGCAGTCTGAGC }\end{array}$ & & \\
\hline F5 & $\begin{array}{l}\text { TACAAAGTTGGTATCATGAAATAAGTCTAC } \\
\text { TAGACTTAGCGCCCAATTACAGTTACCAG }\end{array}$ & & \\
\hline R1 & $\begin{array}{l}\text { CAAAGGCCTCTCTTTCTTGTCCTGACAGCGT } \\
\text { CTGAGTTACATCTTCCAGCAATGGAATG }\end{array}$ & & \\
\hline $\mathrm{R} 2$ & $\begin{array}{l}\text { CTTAGGAGCTGGAATGATGCCTTTCCATCTA } \\
\text { CTACATTATTAATCTGGAGGCCCATCTT }\end{array}$ & & \\
\hline R3 & $\begin{array}{l}\text { TTTCCAGCCCCATCTATCATGATTGGATATT } \\
\text { CTTCAGAGGGCTCAGACTGCTTTT }\end{array}$ & & \\
\hline $\mathrm{R} 4$ & $\begin{array}{l}\text { GAAGTTAGAGAAGGTGACGGTACAAGGGTC } \\
\text { TCAGAAATTAACTACTGGTAACTGTAATT }\end{array}$ & & \\
\hline
\end{tabular}
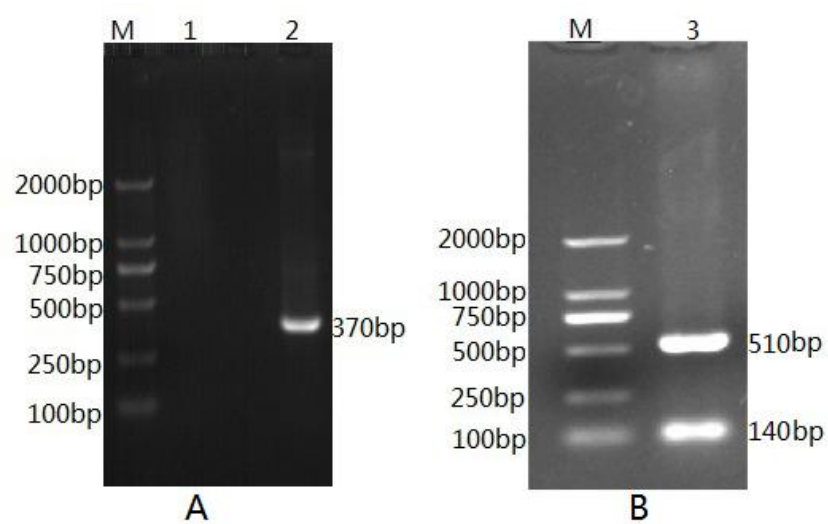

Figure 1. Amplification results of target DNA fragments

A: Overlapping PCR results of EIAV; B: Identification of pMD-19T-EIAV M:DNA marker DL2000; 1: negative control; 2: overlapping PCR products 3:pMD-19T-EIAV PCR products(M13-47/RV-M as primer)

TCAAGAAGTTAGAGAAGGTGACGGTACAAGGGTCTCAGAAATTAACTACTGGTAACTGTAATTGG GCGCTAAGTCTAGTAGACTTATTTCATGATACCAACTTTGTAAAAGAAAAGGACTGGCAGCTGAGGGA TGTCATTCCATTGCTGGAAGATGTAACTCAGACGCTGTCAGGACAAGAAAGAGAGGCCTTTGAAAGA ACATGGTGGGCAATTTCTGCTGTAAAGATGGGCCTCCAGATTAATAATGTAGTAGATGGAAAGGCATCA TTCCAGCTCCTAAGAGCGAAATATGAAAAGAAGACTGCTAATAAAAAGCAGTCTGAGCCCTCTGAAG AATATCCAATCATGATAGATGGGGCTGGAAACAG

Figure 2. Sequencing result 


\section{Optimization of EIAV RT-PCR Reaction Conditions}

To optimize the conditions the RT-PCR reaction were carried out according to the above section with the positive plasmid pMD19-T-EIAV. As shown in Fig. 3, the PCR products were more and bright when the reaction annealing temperature was 50 to $55^{\circ}$ C (lane 1-6). The results of the different concentration of primer (see Fig. 4) showed that there are no different in PCR products with $10 \mu \mathrm{mol} / \mathrm{L}$ primers and $100 \mu \mathrm{mol} / \mathrm{L}$. Considering the specificity and reaction time of the reaction, the PCR reaction conditions were established as $95{ }^{\circ} \mathrm{C}$ for $3 \mathrm{~min}, 35$ cycles of $94{ }^{\circ} \mathrm{C}$ for $40 \mathrm{~s}, 56{ }^{\circ} \mathrm{C}$ for 40 $\mathrm{s}$ and $72{ }^{\circ} \mathrm{C}$ for $45 \mathrm{~s}$, and $72{ }^{\circ} \mathrm{C}$ for $8 \mathrm{~min}$.

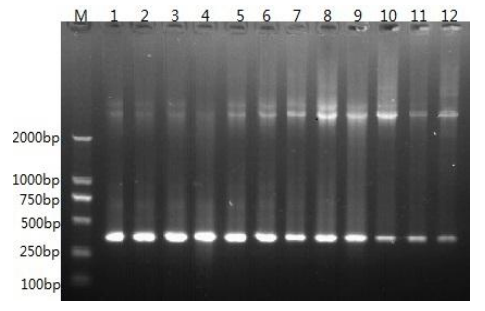

Figure.3:The results of annealing temperature optimization

M:DL2000 DNA

Marker; $1: 50{ }^{\circ} \mathrm{C} ; 2: 50.5{ }^{\circ} \mathrm{C} ; 3: 51.3{ }^{\circ} \mathrm{C} ; 4: 52.7^{\circ} \mathrm{C} ; 5: 54.3{ }^{\circ} \mathrm{C} ; 6: 55^{\circ} \mathrm{C} ; 7: 56.5{ }^{\circ} \mathrm{C} ; 8: 57^{\circ} \mathrm{C} ; 9: 58.8^{\circ} \mathrm{C} ; 10: 61.1{ }^{\circ} \mathrm{C} ; 11: 6$ $3^{\circ} \mathrm{C} ; 12: 65^{\circ} \mathrm{C}$

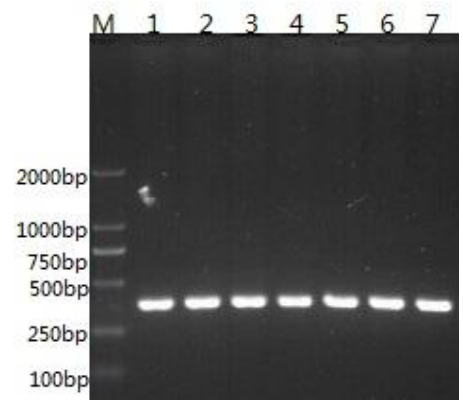

Figure.4: The results of primer concentration optimization

M:DL2000 DNA Marker;1:10 $\mu \mathrm{mol} / \mathrm{L} ; 2: 20 \mu \mathrm{mol} / \mathrm{L} ; 3: 40 \mu \mathrm{mol} / \mathrm{L} ; 4: 50 \mu \mathrm{mol} / \mathrm{L}$; 5:60 $\mu \mathrm{mol} / \mathrm{L} ; 6: 80 \mu \mathrm{mol} / \mathrm{L} ; 7: 100 \mu \mathrm{mol} / \mathrm{L}$

\section{Sensitivity of RT-PCR}

The positive plasmid pMD19-T-EIAV diluting in 10 fold as the template for the sensitivity tests. The results shown in Fig5, the results show RT-PCR reaction in the $1.19 \times 10^{2}$ copies/ $\mu \mathrm{L}$ target gene still can detect a more obvious band, so the RT-PCR detection limits can reach 119 copies $/ \mu \mathrm{L}$.

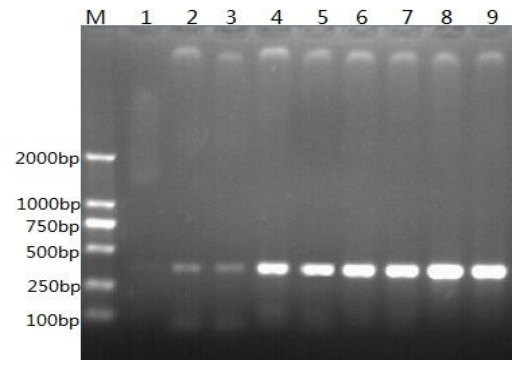

Figure.5: The results of sensitivity test

M:DL2000 DNA Marker;1:11.9 copies/ $\mu \mathrm{L} ; 2: 119$ copies $/ \mu L ; 3: 1190$ copies $/ \mu \mathrm{L}$

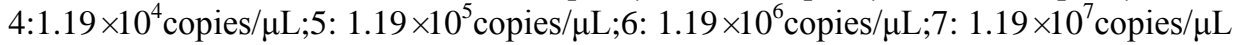




\section{Specificity of RT-PCR}

The specific test was carried out using Proteus, Alternariae, Salmonella, Salmonella, Escherichia coli, Streptococcus and Streptococcus type II. The results are shown in Fig. 6 , the reaction of pMD19-T-EIAV as a template showed a significant band at 370bp (lane1), while the rest of the template reaction was negative (lanes 2-6).

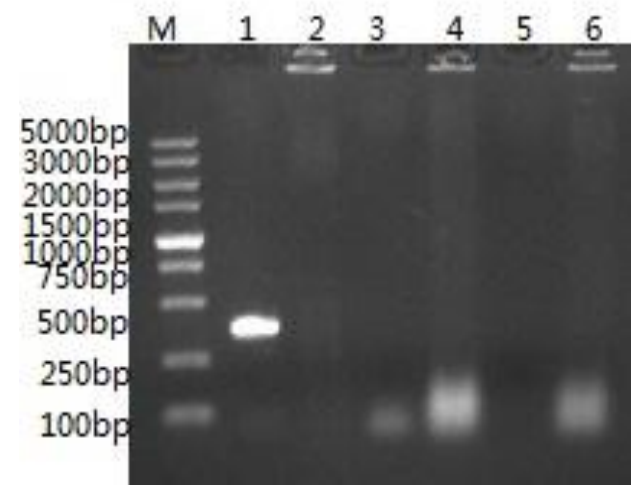

Figure.6: The results of specificity test

M:DL5000 DNA Marker;1: pMD19-T-EAV;2: Proteus;3: Salmonella;4: Escherichia coli;5: Streptococcus type II;6:Stenotrophomonasmaltophilia

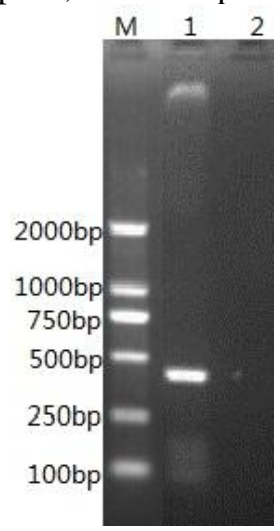

Figure.7: The results of effective experiment

M: DL2000 DNA Marker;1:RT-PCR production of EIAV; 2: negative control

\section{Effective Experiment}

Extracting RNA from Equine infectious anemia reagent agar diffusion test antigen with RNAisoPlus Reagent (BK1501).According Primerscript RT Reagent Kit (BK1901) instructions to reverse transcribecDNA. Obtained cDNA, then doing the validity of the test by using the established PCR reaction conditions and procedures. The results are shown in Fig.7.

\section{Discussion and Conclusions}

RT-PCR, a single-strand RNA is transcribed into a complementary DNA (cDNA) is referred to "reverse", carried out by RNA-dependent DNA polymerase (reverse transcriptase). Subsequently, the other DNA strand deoxynucleotide primer by DNA dependent DNA polymerase and completed with each cycle doubling, that is, normal PCR. With the development of technology, real-time PCR (real-time fluorescence PCR) or a ddPCR (Digital PCR) technique has also been used for quantitative analysis, they are more sensitive and accurate than normal PCR[8,9]. But RT-PCR is widely used in 
the diagnosis of diseases, and may be used for quantitative monitoring of the content of the RNA. According to the current research on EIAV molecular biology detection technology, there have been reports of PCR, multiplex PCR and fluorescence PCR[10-12], all of which are undetectable target genes with EIAV nonstructural protein gag gene. In this study, the gag gene conserved region fragment was also used as the detection target gene.

Here the target gene fragments were synthesized by overlapping PCR, the extension PCR solved the molecular biological level related to the lack of pathogens and avoided the proliferation of high-risk pathogens, including the study of molecular biology diagnostic methods[7,13]. Based on the conserved sequence of equine infectious anemia virus gene, eight bridging extension primers and one pair of specific primers were designed and synthesized. A 370bp target gene fragment was synthesized, and provides a template for the optimization of reaction conditions for RT-PCR detection of EIAV. Then, the RT-PCR method of EIAV was studied by the optimization of reaction conditions such as annealing temperature, specificity and sensitivity monitoring, and the detection of samples. The results showed that the RT-PCR method could amplify the target gene fragment of the EIAV conserved region gene fragment of 370bp. The detection limit corresponding to 119 copies/ $\mu \mathrm{L}$ of objective gene segments, and there were no signs of amplification for detectionProteus, Actinobacillus, Salmonella, Escherichia coli, Stenotrophomonasmaltophilia and Streptococcus type II etc. In conclusion, the results indicate that the established RT-PCR method has a good specificity, sensitivity and practicability, and can be used for differential diagnosis of EIAV.It also provides a scientific basis for the research of high risk pathogens and the lack of pathogen nucleic acid detection technology in the future.

\section{Acknowledgement}

This study was supported by Grants from the planning subject of the College students' innovative training program project of Sichuan agricultural university (1510626062), 'the twelfth five-year-plan' in national science and technology for the rural development in China (2013BAD12B04). Qin Tang, Han Jiaqi, Han Zhang, Yin Wang, Xueping Yao and Lirui Li should also be considered as first authors, Corresponding author: Zexiao Yang, Yin Wang.

\section{References}

[1] J. Chen,Diagnosis and Comprehensive Prevention and Control of Equine Infectious Anemia, J. Journal of Agricultural Catastrophology, 9(2015)15-16, in Chinese.

[2] F.Y. Chen, Veterinary infectious diseases, Fifth ed, Beijing, China Agriculture Press, 2008, in Chinese.

[3] Cook R F, C, Leroux, C.J. Issel, Equine infectious anemia and Equine Infectious Anemia Virus 2013:AReview,J. Veterinary Microbiology,2013 (167) 181-204.

[4] Y.R. Tang, H.Y. Zhang, X.M. Zhang, The influence factors of Equine Infectious Anemia in agar-gel immune diffusion test, J. China Animal Husbandry and Veterinary Medicine Abstract, 32(2016)62-63, in Chinese.

[5] S.Yang, Comparison of ELISA and Agar-gel precipitin test of Equine Infectious Anemia virus antibody, J. Progress in Veterinary Medicine,2(1994), in Chinese. 
[6] J.W. Zhang, The development and application of reverse transcription-polymerase chain reaction, J. Laboratory Medicine and Clinic, 15(2008)941-942, in Chinese.

[7] Y. Wang, Z.X. Yang, X.Q. Han, Development of a complex RT-PCR assay for the detection and differentiation of rabbit hemorrhagic disease virus and European brown hare syndrome virus, J. Chinese Veterinary Science,41(2011)1165-1170, in Chinese.

[8] Y.X. Ni, C.P. Lu, Detection of Rotavirus by Reverse Transcription-polymerase Chain Reaction, J. Chinese Journal of Veterinary Science, 5(1998)437-440, in Chinese.

[9] Y.L. Wu, Q. Cheng, L.X. Yu , Development of a RT-PCR Method for Differentiation of the Wild-Type PEDVs and the Attenuated PEDVs, J. Scientia Agricultural Sinica, 46(2013)4370-4377, in Chinese.

[10]R.F. Cook, S.J. Cook, F. Li, Development of a multiplex real-time reverse transcriptase-polymerase chain reaction for equine infectious anemia virus (EIAV),J. Journal of Virological Methods, 105(2002)171.

[11]J.L. Langemeier, S.J. Cook, R.F. Cook, Detection of equine infectious anemia viral RNA in plasma samples from recently infected and long-term inapparent carrier animals by PCR,J. Journal of Clinical Microbiology, 34(1996)1481-1487.

[12]M.M. Nagarajan, C.Simard, Detection of horses infected naturally with equine infectious anemia virus by nested polymerase chain reaction, J. Journal of Virological Methods, 94(2001)97-109.

[13] X.W. Zhu, L. Li,X.Y. Sang, Development of a TaqMan real-time fluorescent quantitative PCR assay for detection of rift valley fever virus, J. Chinese Journal of Zoonoses,28(2012)315-318, in Chinese. 